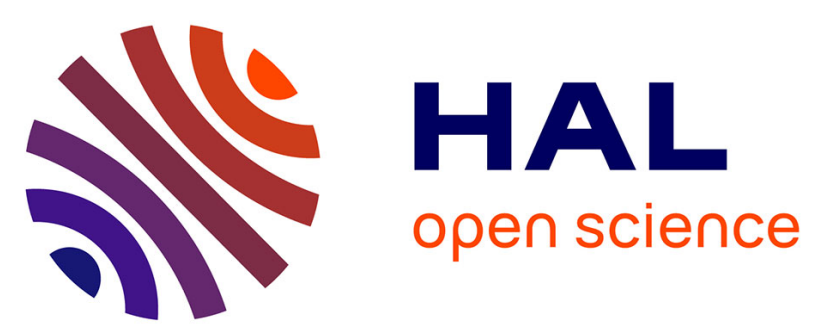

\title{
A new experimental setup designed for the investigation of irradiation of nanosystems in the gas phase: A high intensity mass-and-energy selected cluster beam
}

G. Bruny, S. Eden, S. Feil, R. Fillol, K. El Farkh, M. Harb, C. Teyssier, S.

Ouaskit, H. Abdoul-Carime, B. Farizon, et al.

\section{To cite this version:}

G. Bruny, S. Eden, S. Feil, R. Fillol, K. El Farkh, et al.. A new experimental setup designed for the investigation of irradiation of nanosystems in the gas phase: A high intensity mass-and-energy selected cluster beam. Review of Scientific Instruments, 2012, 83, pp.013305. 10.1063/1.3677845 . in2p3-00662390

\author{
HAL Id: in2p3-00662390 \\ https://hal.in2p3.fr/in2p3-00662390
}

Submitted on 31 May 2021

HAL is a multi-disciplinary open access archive for the deposit and dissemination of scientific research documents, whether they are published or not. The documents may come from teaching and research institutions in France or abroad, or from public or private research centers.
L'archive ouverte pluridisciplinaire HAL, est destinée au dépôt et à la diffusion de documents scientifiques de niveau recherche, publiés ou non, émanant des établissements d'enseignement et de recherche français ou étrangers, des laboratoires publics ou privés. 


\section{A new experimental setup designed for the investigation of irradiation of nanosystems in the gas phase: A high intensity mass-and- energy selected cluster beam}

Cite as: Rev. Sci. Instrum. 83, 013305 (2012); https://doi.org/10.1063/1.3677845

Submitted: 13 September 2011 . Accepted: 28 December 2011 . Published Online: 20 January 2012

G. Bruny, S. Eden, S. Feil, R. Fillol, K. El Farkh, M. M. Harb, C. Teyssier, S. Ouaskit, H. Abdoul-Carime, B. Farizon, M. Farizon, and T. D. Märk

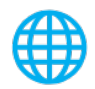

\section{ARTICLES YOU MAY BE INTERESTED IN}

A novel "correlated ion and neutral time of flight" method: Event-by-event detection of neutral and charged fragments in collision induced dissociation of mass selected ions Review of Scientific Instruments 85, 015118 (2014); https://doi.org/10.1063/1.4863015

Correlated ion and neutral time of flight technique combined with velocity map imaging: Quantitative measurements for dissociation processes in excited molecular nano-systems Review of Scientific Instruments 89, 013107 (2018); https://doi.org/10.1063/1.5001162

Measurement of the velocity of neutral fragments by the "correlated ion and neutral time of flight" method combined with "velocity-map imaging"

Review of Scientific Instruments 88, 083101 (2017); https://doi.org/10.1063/1.4991828

Challenge us. What are your needs for periodic signal detection?

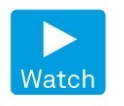

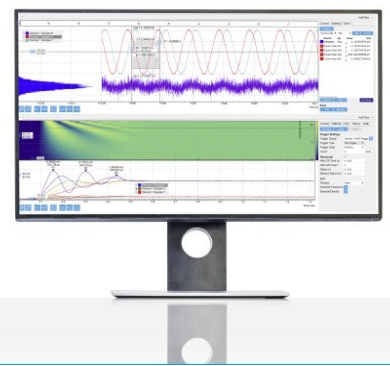
- Instruments 


\title{
A new experimental setup designed for the investigation of irradiation of nanosystems in the gas phase: A high intensity mass-and-energy selected cluster beam
}

\author{
G. Bruny, ${ }^{1}$ S. Eden, ${ }^{2}$ S. Feil, ${ }^{1}$ R. Fillol, ${ }^{1}$ K. El Farkh, ${ }^{1}$ M. M. Harb, ${ }^{1}$ C. Teyssier, ${ }^{1}$ \\ S. Ouaskit, ${ }^{3}$ H. Abdoul-Carime, ${ }^{1}$ B. Farizon, ${ }^{1}$ M. Farizon, ${ }^{1}$ and T. D. Märk ${ }^{4}$ \\ ${ }^{1}$ Institut de Physique Nucléaire de Lyon, UMR5822, Université Lyon 1, F-69622, Villeurbanne, \\ France; Université de Lyon, F-69003, Lyon, France; and CNRS/IN2P3, F-69622, Villeurbanne, \\ France \\ ${ }^{2}$ Department of Physical Sciences, The Open University (OU), Walton hall, Milton Keynes, \\ MK76AA, United Kingdom \\ ${ }^{3}$ Laboratoire de physique de la matière condensée, Faculté des sciences Ben M'sik, \\ Unité associée au CNRST (URAC 10), B.P.7955, Casablanca, Morocco \\ ${ }^{4}$ Institut für Ionenphysik und Angewandte Physik, Leopold Franzens Universität, Technikerstrasse 25, \\ A-6020 Innsbruck, Austria
}

(Received 13 September 2011; accepted 28 December 2011; published online 20 January 2012)

\begin{abstract}
DIAM (Dispositif d'Irradiation d'Agrégats Moléculaires) is a new experimental setup devoted to investigate processes induced by irradiation at the nanoscale. The DIAM apparatus is based on a combination of techniques including a particle beam from high-energy physics, a cluster source from molecular and cluster physics, and mass spectrometry form analytical sciences. In this paper, we will describe the first part of the DIAM apparatus that consists of an ExB double spectrometer connected to a cluster ion source based on a continuous supersonic expansion in the presence of ionizing electrons. This setup produces high intensities of energy-and-mass selected molecular cluster ion beams ( $1000 \mathrm{~s}$ of counts $\mathrm{s}^{-1}$ ). The performance of the instrument will be shown through measurements of 6-8 keV beams of protonated water clusters, $\left(\mathrm{H}_{2} \mathrm{O}\right)_{\mathrm{n}} \mathrm{H}^{+}(\mathrm{n}=0-21)$ and mixed protonated (or deprotonated) water-pyridine cluster ions: $\mathrm{PyrH}^{+}\left(\mathrm{H}_{2} \mathrm{O}\right)_{\mathrm{n}}(\mathrm{n}=0-15), \mathrm{Pyr}_{2} \mathrm{H}^{+}\left(\mathrm{H}_{2} \mathrm{O}\right)_{\mathrm{n}}$ $(\mathrm{n}=0-9)$, and $(\mathrm{Pyr}-\mathrm{H})^{+}\left(\mathrm{H}_{2} \mathrm{O}\right)$. @ 2012 American Institute of Physics. [doi:10.1063/1.3677845]
\end{abstract}

\section{INTRODUCTION}

Radiation science has applications in a wide range of activities including nano-lithography, ${ }^{1}$ the food industry, ${ }^{2}$ and medical therapies to treat tumors. ${ }^{3}$ Furthermore, high-energy particles can induce unwanted effects such as genomic diseases (notably cancers and mutations). Therefore, there is a strong motivation to understand interactions of the radiation with biological media in a greater detail. Knowledge gained from fundamental experiments leads to potential applications in (i) predicting and controlling the effects of ionizing radiation, (ii) improving radiation technology or strategies in therapy, ${ }^{4}$ and (iii) opening new perspectives for the elucidation of the radiation dose in living systems.

Progress in understanding radiation phenomena on a molecular-scale and the development of molecular analysis techniques have triggered key questions related to the effects of ionizing radiation in biological tissue. ${ }^{5-9}$ For instance, recent technical advances have opened possibilities for the study of biological molecules seeded in clusters of water molecules, and hence an entirely new perspective. ${ }^{10}$ This intermediate step between the isolated molecule and the condensed phase has great potential as a target medium for research into the effects of ionizing radiation. Indeed the possibility to form a cluster with a well-defined composition, for instance, a small "biomolecule" solvated by a given number of water molecules, offers a unique opportunity to quantify the impact of environment on the irradiation process. Moreover, this well-controlled (and possibly small) size provides exceptional opportunities to obtain direct and complete microscopic descriptions of the irradiation process and, to some extent, the subsequent relaxation pathways.

Here we present the first part of a new experimental setup designed for the investigation of irradiation of nanosystems in the gas phase, DIAM (Dispositif d'Irradiation d'Agrégats Moléculaires). The apparatus produces well-defined highintensity beams of mass-and-energy selected molecular and cluster ions. Section II describes the design and the function of each part of the experimental setup: the cluster source, the ionization and acceleration parts, and the ExB double focusing mass spectrometer. A set of simulations is presented that were used to optimize the beam in the different parts of the system. In Sec. III, the characterization of the cluster source and the performance of the $E x B$ mass spectrometer will be discussed, i.e., the mass and the energy resolutions. The performance of this setup will be illustrated by results obtained for homogeneous protonated water clusters and heterogeneous protonated/deprotaneted water-pyridine cluster ions.

\section{EXPERIMENTAL}

The setup comprises three essential parts (Figure 1): the cluster source, the ionization and acceleration zone, and the $E x B$ double focusing mass spectrometer. These parts are discussed below in Secs. II A-II C. 


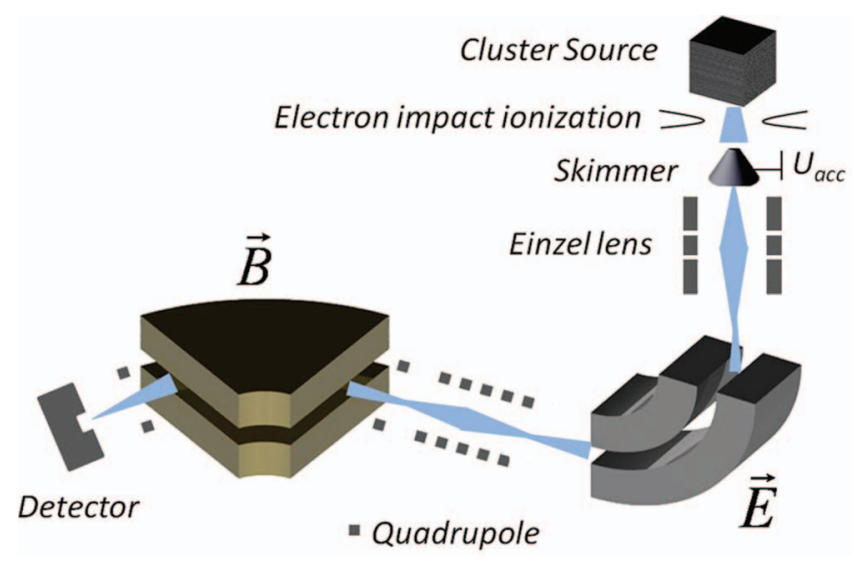

FIG. 1. (Color online) Experimental setup.

\section{A. Cluster source}

The cluster beam is produced in a continuous supersonic expansion of the investigated molecular gas (mixture) through an orifice thus allowing to produce an intense cluster beam. ${ }^{1-14}$ The supersonic expansion essentially depends on the diameter of the pinhole, the pressures before and after the orifice, and the stagnation temperature $\mathrm{T} 0$. Figure 2 is a schematic representation of the present cluster source. It comprises a reservoir connected to a stainless steel diaphragm with a central pinhole of $20 \mu \mathrm{m}$ diameter (Oxford instruments). The reservoir, equipped with a heating element, contains the molecular sample (liquid at room temperature, e.g., water). The pressure in this gas-line is measured by a manometer (M). A carrier-gas (He and Ar) can be introduced through a valve $(\mathrm{V})$. The diaphragm is mounted on the first chamber in which an operating pressure of $10^{-4}$ mbar is maintained by a diffusion pump (1200 1/s). This diaphragm can be heated up to $120^{\circ} \mathrm{C}$ during experiments to prevent condensation that would close the orifice. The second chamber is pumped to $10^{-6}$ mbar by a second $1200 \mathrm{l} / \mathrm{s}$ diffusion pump.

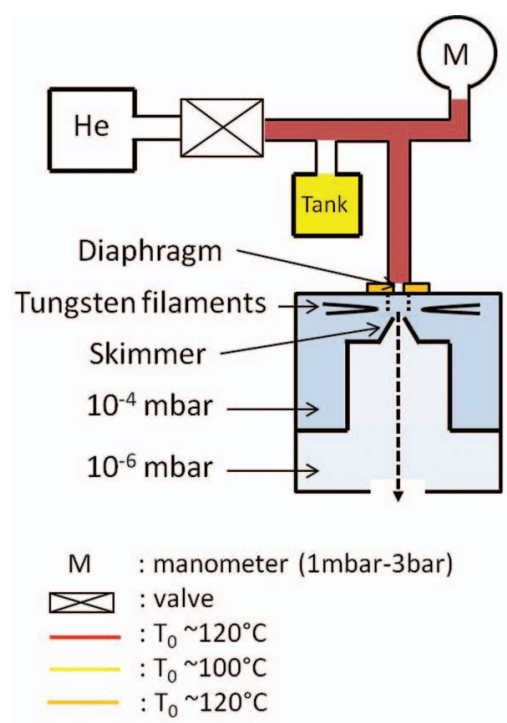

FIG. 2. (Color online) Schematic diagram of the cluster source, including the ionization and acceleration sections.

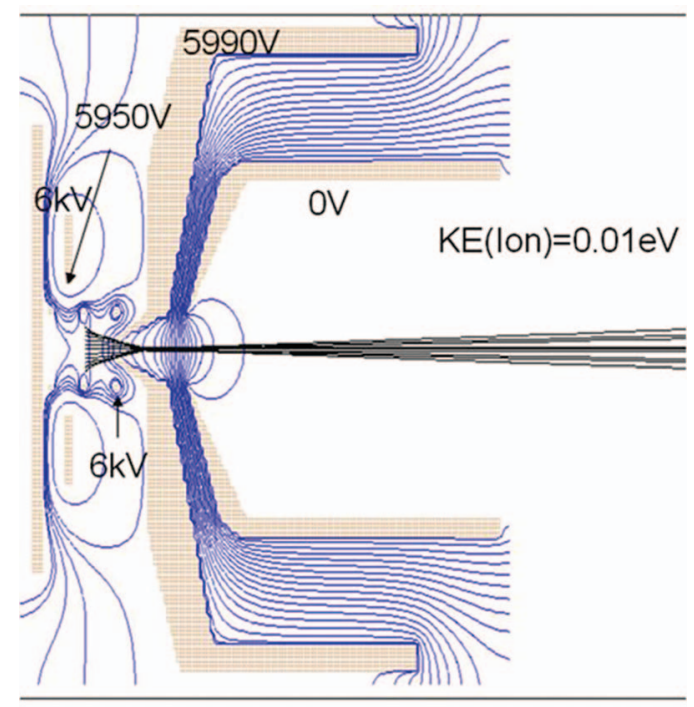

FIG. 3. (Color online) SIMION ${ }^{\circledR}$ simulations of the trajectories of ions produced by electron impact (emitted from tungsten filaments held at $-50 \mathrm{~V}$ with respect to the high-voltage source), accelerated through $6 \mathrm{kV}$ and with an initial energy of $0.01 \mathrm{eV}$ in the direction of the acceleration. All trajectories enter into the spectrometer by applying an extraction voltage of $10 \mathrm{~V}$. Equipotential lines are also shown.

Both chambers are connected via a skimmer (cone height $7 \mathrm{~mm}$ with a $2 \mathrm{~mm}$ opening) to select the core of the beam.

\section{B. Ionization, acceleration, and focusing of the cluster beam}

After the neutral clusters are produced, they are ionized by a $50-90 \mathrm{eV}$ electron beam. Two tungsten filaments of diameter $0.51 \mathrm{~mm}$ are mounted in the first chamber a few millimeters below the diaphragm. A current of 10-20 A can be applied to the filaments through a Lambda ZUP 6V-66A power supply. The electron beam ionizes and dissociates the neutral clusters, producing a variety of positive, negative, and neutral species. In the present work we are interested in positive ions. The first chamber is held at high voltage, $U_{\text {acc }}$ $=1-20 \mathrm{kV}$ (supplied by a Spellman SL-1200 unit), while the second chamber is grounded. Thus, positively charged species are accelerated and enter the second chamber through the skimmer. To optimize the transmission of ions through the skimmer, an extraction voltage, $U_{\text {extr }}=0-100 \mathrm{~V}$ (supplied by a Knürr Heinzig LNG 100-5 unit) is applied to the skimmer. Figure 3 shows a simulation of the trajectories of ions by SIMION ${ }^{\circledR} .{ }^{15}$ Equipotential lines are also represented. The initial starting energy of the ions has been taken as $10 \mathrm{meV}$ (Ref. 16) and the simulation shows that all the ions are transmitted into the second chamber. As will be discussed in Sec. III A, the extraction voltage significantly enhances the signal at the detector.

An electrostatic Einzel lens located $154 \mathrm{~mm}$ downstream of the skimmer orifice focuses the accelerated cluster ions onto the deflector object plane (Sec. II C). This lens is composed of three circular electrodes of diameter $40 \mathrm{~mm}$. The two outer electrodes are separated from the central electrode by a distance of $7 \mathrm{~mm}$. The central electrode has a thickness of $14 \mathrm{~mm}$ and is held at a voltage $U_{\mathrm{EL}}$, while the outer 
electrodes are grounded. An analytical calculation based on the matrix transfer method ${ }^{17,18}$ has been used to simulate the focusing of ion trajectories by the electrostatic lens. Hence, for a given acceleration voltage $U_{\text {acc }}$, we are able to evaluate the optimal value of $U_{\mathrm{EL}}$ at which the focal plane of the ion trajectories coincides with the object plane of the deflector. To measure the resultant ion current, a movable Faraday cup is placed $522 \mathrm{~mm}$ from the last electrode of the Einzel lens.

\section{ExB double focusing mass spectrometer}

The key elements of the $E x B$ double focusing mass spectrometer are an electrostatic deflector (ED) and an electromagnet sector (EM) (Fig. 1). The electrostatic deflector enables the kinetic energy of charged particles to be analyzed in the vertical plane. Indeed, this spherical ED (radius $500 \mathrm{~mm}$ and deflection angle $90^{\circ}$ ) focuses the particle beam in the two directions perpendicular to the propagation. The distance between its electrodes is $40 \mathrm{~mm}$; its unwound length is $785 \mathrm{~mm}$. The potential is applied by a Fug-6500 V power supply, controlled by a NI PXI-6704 card. The entrance of the ED is positioned $1132 \mathrm{~mm}$ downstream of the exit of the Einzel lens.

The electromagnetic sector selects the molecular cluster ions according to their momenta in the horizontal plane and allows for mass analysis for energy-selected beams. It has a radius of $374 \mathrm{~mm}$, an exit angle of $60^{\circ}$ relative to the incident beam, and is powered by a generator that can provide a maximum current of $200 \mathrm{~A}$. The maximum attainable magnetic field is $\sim 16$ kGauss (1.6 T). Furthermore, it is noteworthy that the smaller the initial energy for the incident ion, the larger the accessible mass range. For example, from a singly ionized cluster beam accelerated to $6 \mathrm{keV}$, masses up to $2700 \mathrm{Th}$ (atomic mass unit) are accessible, corresponding to 150 water molecules per cluster. Increasing the ion acceleration voltage to $30 \mathrm{kV}$, the setup allows only the selection of masses up to $500 \mathrm{Th}$, corresponding to 27 water molecules.

Although the magnet provides horizontal focusing, two quadrupoles are located at its input and output to provide a vertical focusing of the beam. A set of five further quadrupoles, regularly spaced and rotated $45^{\circ}$ around the axis in the direction of the beam, have been installed in positions calculated for optimal transmission of the beam between the deflector and the magnet. The role of this setup is to rotate the beam by $90^{\circ}$, so that the energy dispersion in the vertical direction is transformed to momentum dispersion in the horizontal direction. The quadrupole lenses are alternately converging-diverging in the transverse direction (Ox, the beam direction), and alternately diverging-converging in the longitudinal direction (Oy). For reasons of symmetry, the quadrupoles 1qx1 $\left(\mathrm{N}^{\circ} 1\right)$ and $5 \mathrm{qx} 1\left(\mathrm{~N}^{\circ} 5\right)$ are held at the same voltage, as are the quadrupoles $2 \mathrm{qy} 1\left(\mathrm{~N}^{\circ} 2\right)$ and $4 \mathrm{qy} 1\left(\mathrm{~N}^{\circ} 4\right)$. Only the central quadrupole $3 \mathrm{qx} 1\left(\mathrm{~N}^{\circ} 3\right)$ has an independent voltage. By simply changing of the polarity of the five quadrupoles, this arrangement enables to divert in opposite horizontal directions. Moreover, adjustable slits are located at the image plane of the electrostatic deflector (vertical) and at the object plane of the magnet (horizontal). These vertical and horizontal slits are used to define the energy dispersion of the beam at the respective exits of the deflector and the quadrupole quintuplet.

Two sets of deflection plates or "steerers", located before the electrostatic deflector and before the magnetic sector, are used to optimize the beam guidance. Each steerer is composed of four pairs of $20 \times 20 \mathrm{~mm}$ parallel plates; the distance between each two pairs of plates is $1.5 \mathrm{~mm}$; the distance between plates of the same pair is $20 \mathrm{~mm}$. The pressure in the spectrometer, pumped by three turbomolecular pumps (250 $1 / \mathrm{s})$, is maintained below $10^{-6}$ mbar.

The performance of the $E x B$ spectrometer has been simulated using the TRANSPORT code. ${ }^{19}$ Briefly, this simulation represents a charged particle by a vector of six components (positions, angles, and momentum). Each electrostatic optic element (EOE) of the beam path, i.e., ED, EM, and quadrupoles, is modeled by a $6 \times 6$ transfer matrix reflecting the action on the path of the ions. The new coordinates of the trajectory of the ion after crossing the element is given by the product of the initial vector and the transfer matrix. All these coordinates are defined relative to a central trajectory, for which all these parameters are set to zero. According to this calculation, the object distance and the image distance of the deflector are, respectively, $951 \mathrm{~mm}$ and $263 \mathrm{~mm}$, the total lateral dispersion of the spectrometer is $15.27 \mathrm{~mm} \%$, and double focusing is achieved when

$$
2 R_{36 e}+\frac{R_{16 m}}{R_{11 m}}=0,
$$

where $R_{36 \mathrm{e}}$ is a coefficient of the transfer matrix associated with the electrostatic deflector, $R_{16 \mathrm{~m}}$ and $R_{11 \mathrm{~m}}$ are coefficients of the transfer matrix associated with the magnet and $R_{36 \mathrm{e}}$ represents the lateral dispersion of the deflector, and $R_{11 \mathrm{~m}}$ is the magnification term of the magnetic section.

The resolving power of a double focusing spectrometer is given by the formula,

$$
\frac{m}{\Delta m}=\frac{1}{2} \frac{\rho_{m}(1+|G|)}{S|G|+C},
$$

where $\rho_{\mathrm{m}}$ is the radius of the magnet, $G=\mathrm{GeGm}$ is the product of the gains of the electrostatic and magnetic parts, $S$ is the opening of slits located after the deflector, and $C$ is the opening of slits located before the magnet. In the present case, the magnet has a radius $\rho=0.374 \mathrm{~m}$, the total magnification $G$ is 0.527 for slit widths of $1 \mathrm{~mm}$. The theoretical resolution expected from the simulation of the spectrometer is $\Delta \mathrm{m} / \mathrm{m}$ $=1 / 187$.

To visualize and to characterize the ion beam (i.e., its position, shape, and intensity) inside the spectrometer, two multi-wire plane chambers, MWPCs are installed along the beam line: the first is located $24 \mathrm{~cm}$ after the vertical slits and the second $28 \mathrm{~cm}$ from the horizontal slits. Each MWPC is composed of a wire plane, an amplifier module, and a synchronization module. The wire plane comprises 32 wires spaced by $1 \mathrm{~mm}$ : 16 vertical numbered from 0 to 15 and 16 horizontal numbered from 16 to 31 . When an ion collides with a wire, the current generated is amplified and then converted into voltage. The signal extracted from the 32 wires is then 
merged by a multiplexing module. The apparatus is controlled via a home-designed software written under LabVIEW ${ }^{\circledR}(\mathrm{Na}-$ tional Instruments) environment and the i/o signals interface is provided using a NI PXI-6225 acquisition card.

Finally, the charged particles are collimated by a slit of diameter of $2 \mathrm{~mm}$ and detected by a channeltron (Dr. Sjuts) detector installed at few tens of centimeters after the exit port of the electro-magnet.

\section{PERFORMANCE OF THE EXB DOUBLE FOCUSING MASS SPECTROMETER AND RESULTS}

\section{A. Characterization of the cluster source}

The performance of our $E x B$ mass spectrometer is illustrated through two examples from supersonic beam expansions of water molecules and an ad-mixture of pyridine-water molecules. In the later experiments, the reservoir is loaded with liquid pyridine (99\% purity) and water (spectroscopic grade) provided from Aldrich Sigma Ltd. The reservoir is heated to $120^{\circ} \mathrm{C}$, while the temperatures of the gas line and the diaphragm are maintained at $100{ }^{\circ} \mathrm{C}$ and $120^{\circ} \mathrm{C}$, respectively, to prevent condensation that would obstruct the $20 \mu \mathrm{m}$ pinhole. Right after their formation, the neutral clusters are interacting with a beam of $50 \mathrm{eV}$ electrons. The positively charged species are then accelerated through $U_{\text {acc }}=6 \mathrm{kV}$. After travelling through the mass spectrometer, the ions are detected by a channeltron detector. We will discuss below the effect of some of the EOEs.

First we observe the action of the extraction voltage, $U_{\text {extr }}$ Figure 4(b) exhibits the mass spectrum of protonated water clusters, $\mathrm{H}^{+}\left(\mathrm{H}_{2} \mathrm{O}\right)_{\mathrm{n}}$, taken at $\mathrm{U}_{\text {extr }}=0 \mathrm{~V}$. The main peaks are separated by $18 \mathrm{Th}$ characteristic of one water unit. Since the high intensity ( $>5000$ counts/s) of the clusters with $n=1$ and 2 would degrade the performance of the detector, the mass spectrum intentionally starts from $n=3$. Note that the intensity of the seven-mer of protonated water cluster, $\mathrm{n}=7$ with $127 \mathrm{Th}$, is about $<200$ counts/s. The signal structures

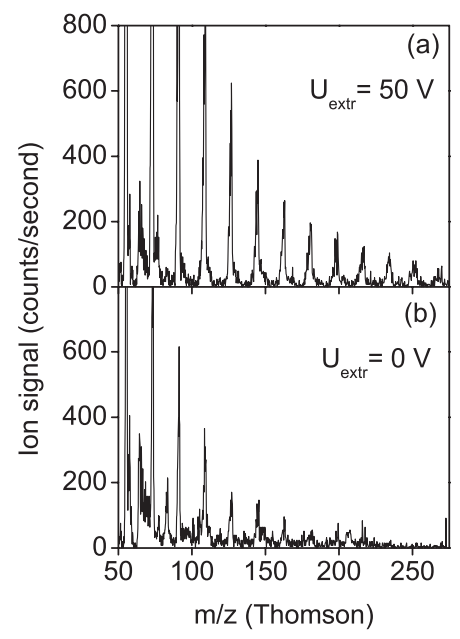

FIG. 4. Two experimental mass spectra of protonated water clusters $\mathrm{H}^{+}\left(\mathrm{H}_{2} \mathrm{O}\right)_{\mathrm{n}}$ obtained with the same acceleration voltage $(6 \mathrm{kV})$ but with two different extraction voltages: 0 and $50 \mathrm{~V}$. These spectra, showing the variation of the ion signal with the mass/charge ratio $(\mathrm{m} / \mathrm{z})$, demonstrate that the peak intensity increases strongly with the extraction voltage.

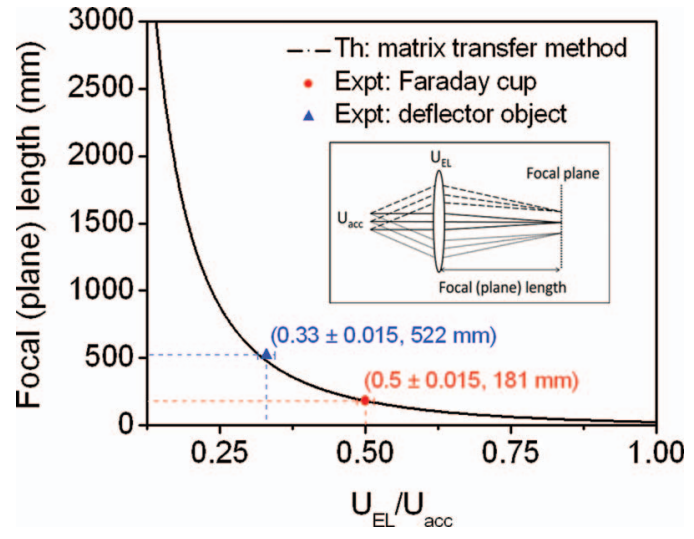

FIG. 5. (Color online) Variation of the focal (plane) length of the Einzel lens as a function of the ratio of applied voltages $U_{\mathrm{EL}} / U_{\mathrm{acc}} \mathrm{U}_{\mathrm{EL}}$ is the voltage applied to the inner electrode of the Einzel lens and $U_{\text {acc }}$ is the acceleration voltage. The focal length is defined as the distance from the exit (i.e., the third electrode) of the lens to the focal point. The focal length decreases with increasing $U_{\mathrm{EL}} / U_{\mathrm{acc}}$ (for $0<U_{\mathrm{EL}} / U_{\mathrm{acc}}<1$ ). Two experimental points corresponding to the position of the Faraday cup (blue triangle) and the position of the deflector object plane (red circle) confirm the validity of the theoretical curve (black line) calculated using the matrix transfer method.

observed between $n=3$ and $n=4$ are attributed to impurity ions. In Figure 4(b), an extraction voltage of $50 \mathrm{~V}$ is applied. The striking feature is the strong increase in the ion yields; for instance, the protonated seven-mer yield is now more than 650 counts/s (gain by a factor of 3 ). Thus, we typically use $U_{\text {extr }}=80 \mathrm{~V}$ and the ion yield intensity is on average by at least one order of magnitude larger than with $U_{\text {extr }}=0 \mathrm{~V}$. These results are in agreement with the SIMION ${ }^{\circledR}$ simulations previously discussed (Figure 3).

The next step for the optimization concerns the Einzel lens that focuses the ion beam at the entrance of the electrostatic deflector. Figure 5 shows the simulation of the position of the focal plane, taken with respect to the position of the exit of the Einzel lens, as a function of $U_{\mathrm{EL}} / U_{\mathrm{acc}}$, the ratio of the acceleration and lens voltages. As a movable Faraday cup is placed at $522 \mathrm{~mm}$ from the exit of the Einzel lens, we are able to confirm that the theoretical optimal $U_{\mathrm{EL}} / U_{\mathrm{acc}}$ ratio of 0.33 corresponds to the maximum of the detected ion signal (blue triangle). The second test point would be localized at the object plane position of the electrostatic deflector, for which we do not have a direct probe. As the object distance of the deflector is equal to $951 \mathrm{~mm}$ according to the calculation of Hadinger, ${ }^{14}$ and the distance between the exit of the Einzel lens and the entry of the deflector is $1132 \mathrm{~mm}$, the object plane of the deflector where the Einzel lens should focus must be within $181 \mathrm{~mm}(1132-951 \mathrm{~mm})$ from the exit of the lens. Experimentally, from the observation of the beam profile on the first wire chamber, we find that the maximum intensity is reached when applying a $U_{\mathrm{EL}}$ voltage corresponding to $U_{\mathrm{EL}} / U_{\mathrm{acc}}=0.5$ (red circle). Then, as seen in Figure 5, the two experimental points $(0.33 \pm 0.01,522)$ and $(0.5$ $\pm 0.01,181)$, coincide with the theoretical curve.

\section{B. Performance of the ExB mass spectrometer}

Figure 6 illustrates the profile of a cluster ion beam detected on the two MWPCs. On MWPC1, the beam is 


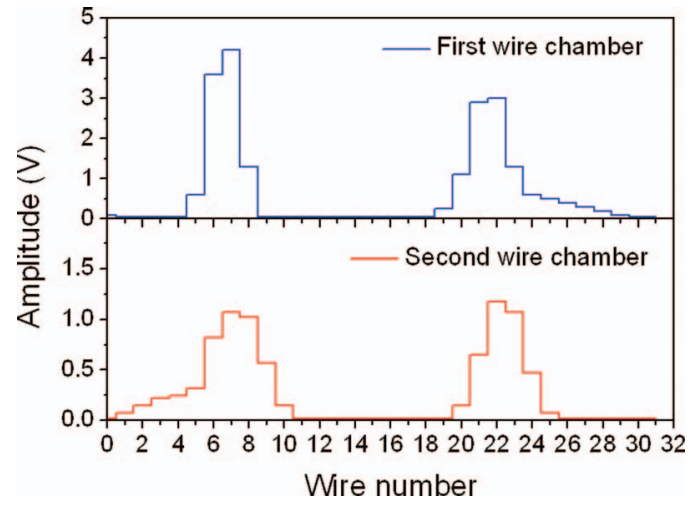

FIG. 6. (Color online) Beam profile displayed on the two wire chambers. The upper graph corresponds to the first chamber installed at the outlet of the electrostatic deflector. The lower graph corresponds to the second chamber installed after the magnet. The acceleration voltage is $8 \mathrm{kV}$. In the second chamber, the beam profile is reversed with respect to the first, due to the effect of the quadrupole quintuplet located between the two wire chambers.

centered on the 8th wire (vertical) and the 22nd wire (horizontal), showing that the beam is well centered in the beam line. The beam extends across four wires, indicating a width of 4 $\mathrm{mm}$. On MWPC2, the beam profile is reversed with respect to MWPC1, illustrating the rotating effect on the beam of the quadrupole quintuplet located between the two MWPCs. In this case, the transmission between the two MWPCs, through the quadrupole quintuplet is $50 \%$. It should be noted that we usually work with an intensity corresponding to several tens of nA to visualize the beam on the MWPCs.

As the cluster ion beam enters the electromagnet at a given velocity, the trajectories of the ion species in the beam differ according their masses. A mass spectrum of the beam is obtained at the exit of the EM sector by varying the magnetic field. To detect the mass-energy selected ions on the detector, the ion current must be lowered to avoid the damage of the detector. This is achieved by decreasing the sample reservoir temperature and/or the intensity of the ionizing electron beam by reducing the current through the tungsten filaments. Under typical operating conditions, the maximum ion current is of the order of few nA.

We now illustrate the performance of our ExB mass spectrometer with an example of heterogeneous pyridine-water cluster ions..$^{20,21}$ Figure 7 shows the mass spectrum recorded using the optimized experimental conditions given in the Table I. This mass spectrum covers the range 100-350 Th. Indeed, below $100 \mathrm{Th}$, it would exhibit only the distribution of protonated water cluster with size below five water units (i.e., $\mathrm{n}<5$ ) as shown in Figure 4, however, with a much higher intensity.

The first noteworthy result concerns the high intensity of the ion signal. The yields of cluster ions with $\mathrm{m} / \mathrm{z}$ up to 300 Th exceed 1000 counts/sec. The usual distribution of molecular clusters exhibits an exponential decrease in the ion yield as a function of the cluster size. ${ }^{22}$ Hence in the low mass range $(<100 \mathrm{Th}$ and not shown in the figure), the intensity is even larger. The intensity can be increased further, for example, by increasing the electron current for the neutral cluster ionization or the stagnation pressure.

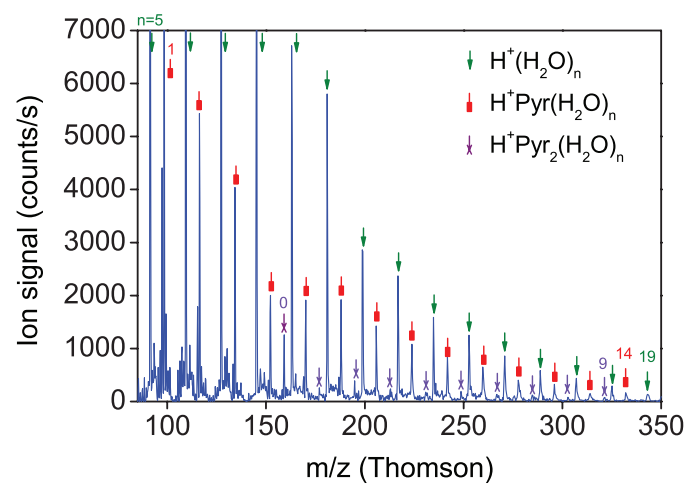

FIG. 7. (Color online) Cluster ion mass spectrum showing the presence of protonated water clusters $\mathrm{H}^{+}\left(\mathrm{H}_{2} \mathrm{O}\right)_{n}$ with $5 \leq \mathrm{n} \leq 19$ (triangle labels), heterogeneous protonated pyridine molecule/water clusters $\mathrm{Pyr}^{+}\left(\mathrm{H}_{2} \mathrm{O}\right)_{n}$ with 1 $\leq \mathrm{n} \leq 14$ (square labels), and mixed protonated pyridine dimer/water clusters $\mathrm{Pyr}_{2} \mathrm{H}^{+}\left(\mathrm{H}_{2} \mathrm{O}\right)_{\mathrm{n}}$ with $0 \leq \mathrm{n} \leq 9$ (cross labels). For each series, the intensity of the cluster ions decreases exponentially with mass/charge. Experimental conditions see Table I.

The $\mathrm{m} / \mathrm{z}$ range presented in Figure 7 shows protonated pyridine/water clusters, $\operatorname{PyrH}^{+}\left(\mathrm{H}_{2} \mathrm{O}\right)_{\mathrm{n}}(1 \leq \mathrm{n} \leq 14)$ and protonated pyridine dimer/water clusters, $\mathrm{Pyr}_{2} \mathrm{H}^{+}\left(\mathrm{H}_{2} \mathrm{O}\right)_{\mathrm{n}}(0 \leq \mathrm{n}$ $\leq 9$ ), in addition to the protonated water peaks. For each of these cluster ion series, the shape of the spectrum exhibits an exponential decrease, as in the case of mass spectra of pure protonated water clusters.

Figure 8 shows the $\mathrm{m} / \mathrm{z}$ range $177-185$ Th of the mass spectrum. The observed peak corresponds to the $\mathrm{H}^{+}\left(\mathrm{H}_{2} \mathrm{O}\right)_{10}$ cluster, with $\mathrm{m} / \mathrm{z}=181 \mathrm{Th}$. In this experiment, the cluster ion has been accelerated up to $6 \mathrm{kV}$ prior to detection. We measure the half width at full maximum of the peak to be $1.06 \mathrm{Th}$. Thus, the experimental mass resolution $\Delta m / m$ is found to be $1.06 / 181$, which is in good agreement with the theoretical prediction of $1 / 187$. It is noteworthy that this resolution can be improved by closing the slits at the exit of the electrostatic deflector.

TABLE I. Experimental conditions of the mass spectrum of mixed protonated pyridine/water clusters shown in Figure 7.

\begin{tabular}{lc}
\hline Acceleration voltage & $6 \mathrm{kV}$ \\
Extraction voltage & $91 \mathrm{~V}$ \\
Electron energy & $50 \mathrm{eV}$ \\
Electron current & $1 \mathrm{~mA}$ \\
Innerelectrode Einzel lens voltage & $3 \mathrm{kV}$ \\
Diaphragm temperature & $100^{\circ} \mathrm{C}$ \\
Intel gas temperature & $125^{\circ} \mathrm{C}$ \\
Tank temperature & $116^{\circ} \mathrm{C}$ \\
Pressure in ionization chamber & $3.9 \times 10^{-4} \mathrm{mbar}$ \\
Pressure inside the spectrometer & $5 \times 10^{-6} \mathrm{mbar}$ \\
Deflector voltages & $\pm 480 \mathrm{~V}$ \\
Quadrupoles voltages & \\
1qx1 & $-125.02 \mathrm{~V}$ \\
5qx1 & $-125.02 \mathrm{~V}$ \\
2qy1 & $116.98 \mathrm{~V}$ \\
4qy1 & $116.98 \mathrm{~V}$ \\
3qx1 & $-154.42 \mathrm{~V}$ \\
1qy2 & $-23.06 \mathrm{~V}$ \\
2qy2 & $-23.06 \mathrm{~V}$ \\
\hline \hline
\end{tabular}




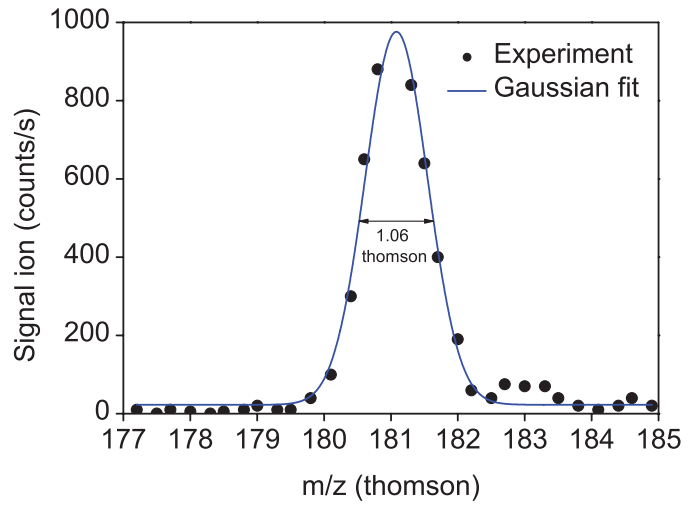

FIG. 8. (Color online) Intensity of $\mathrm{H}^{+}\left(\mathrm{H}_{2} \mathrm{O}\right)_{10}$ cluster beam (181 Th) accelerated through $6 \mathrm{kV}$. The full width at half maximum (FWHM) is $1.06 \mathrm{Th}$, which gives an experimental resolution of $0.58 \%$.

Figure 9 shows the $\mathrm{m} / \mathrm{z}$ 85-135 Th of the entire mass spectrum of mixed (water-pyridine) cluster ions presented in Fig. 7. Four types of peaks are presented: the most intense peaks correspond to protonated water clusters $\mathrm{H}^{+}\left(\mathrm{H}_{2} \mathrm{O}\right)_{n}$ (n $=5,6,7)$, followed by protonated $\mathrm{Pyr} \mathrm{H}^{+}\left(\mathrm{H}_{2} \mathrm{O}\right)_{\mathrm{n}}(\mathrm{n}=1,2,3)$ clusters, and then $\operatorname{Pyr}^{+}\left(\mathrm{H}_{2} \mathrm{O}\right)_{n}(\mathrm{n}=1,2)$, while the least intense peak is the dehydrogenated $(\mathrm{Pyr}-\mathrm{H})^{+}\left(\mathrm{H}_{2} \mathrm{O}\right)$ cluster ion. The pyridine electron-impact mass spectrum from the NIST Chemistry WebBook (typically $\sim 70 \mathrm{eV}$ electron impact) exhibits a peak at 79 Th corresponding to ionized pyridine but also a weaker peak at 78 Th corresponding to deprotonated pyridine $\left(\mathrm{C}_{5} \mathrm{H}_{4} \mathrm{~N}^{+}\right)$. We also observe a peak at $78 \mathrm{Th}$

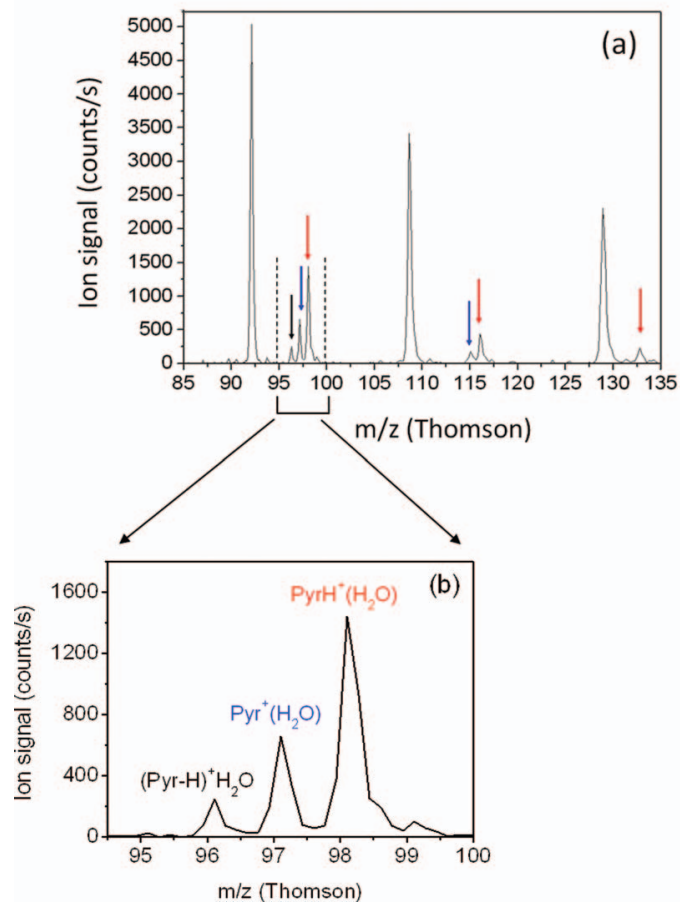

FIG. 9. (Color online) (a) Mass spectrum of mixed water-pyridine cluster ions. The most intense peaks correspond to the protonated water clusters $\mathrm{H}^{+}\left(\mathrm{H}_{2} \mathrm{O}\right)_{\mathrm{n}}(\mathrm{n}=5-7)$. The additional peaks are assigned to $\operatorname{PyrH}^{+}\left(\mathrm{H}_{2} \mathrm{O}\right)_{\mathrm{n}}$ $(\mathrm{n}=1-3), \mathrm{Pyr}^{+}\left(\mathrm{H}_{2} \mathrm{O}\right)_{\mathrm{n}}(\mathrm{n}=1-2)$, and $(\mathrm{Pyr}-\mathrm{H})^{+}\left(\mathrm{H}_{2} \mathrm{O}\right)$. (b) Zoom of the 94.5-100 Th range. For all $\mathrm{n}$ values, the hydrated protonated pyridine is the most intense type of mixed cluster ion.

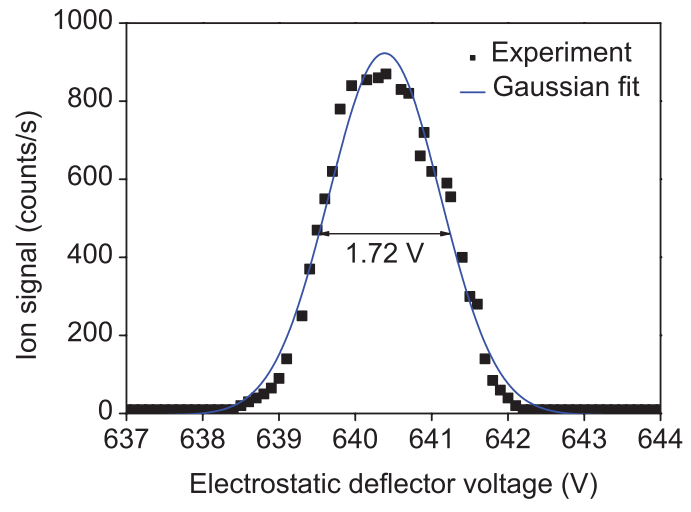

FIG. 10. (Color online) Signal of $\mathrm{H}^{+}\left(\mathrm{H}_{2} \mathrm{O}\right)_{5}$ cluster ions as a function of voltage across the electrostatic deflector for an acceleration voltage of $8 \mathrm{kV}$. The full width at half maximum (FWHM) is $1.72 \mathrm{~V}$, giving a beam energy of $0.27 \%$.

and a further peak at 96 Th corresponding to the dehydrogenated $(\mathrm{Pyr}-\mathrm{H})^{+}\left(\mathrm{H}_{2} \mathrm{O}\right)$ cluster. Figure 9 (a) shows that protonated pyridine is the major molecular species among the three types of pyridine ions. By magnifying the spectrum in the $\mathrm{m} / \mathrm{z}$ range of 95-100 Th (Fig. 9(b)), three peaks are clearly observable at $\mathrm{m} / \mathrm{z}=96-98 \mathrm{Th}$. These peaks separated by $1 \mathrm{Th}$ are attributed to $(\mathrm{Pyr}-\mathrm{H})^{+}\left(\mathrm{H}_{2} \mathrm{O}\right), \mathrm{Pyr}^{+}\left(\mathrm{H}_{2} \mathrm{O}\right)$, and $\mathrm{Pyr} \mathrm{H}^{+}\left(\mathrm{H}_{2} \mathrm{O}\right)$ clusters, further demonstrating the resolution of our $\mathrm{ExB}$ mass spectrometer.

The last characteristic of the $E x B$ mass spectrometer to be discussed here concerns the energy distribution of the detected ions. We also measured the energy distribution of cluster ions for a given mass. By fixing all parameters of the experiment, we varied the voltage across the electrostatic deflector. Figure 10 shows the measured energy distribution of $\mathrm{H}^{+}\left(\mathrm{H}_{2} \mathrm{O}\right)_{5}$ cluster ions $(91 \mathrm{Th})$ for an acceleration voltage of $U_{\text {acc }}=8 \mathrm{kV}$. For a deflection voltage of $640 \mathrm{~V}$, the full width at half maximum is $1.72 \mathrm{~V}$, which amounts to an energy width of $0.26 \%$. This resolution can be improved further by reducing the slits at the exit of the electrostatic deflector.

\section{CONCLUSION}

Nanoscale characterization of irradiation in biomolecular systems requires observation of novel features which are now achievable with the recent technical progress. The present work is the first part in the development of DIAM, which is a new experimental setup devoted to irradiation of biomolecular clusters at the Institut de Physique Nucleaire de Lyon. The DIAM apparatus is based on a combination of techniques including a particle beam from high-energy physics, a cluster source from molecular and cluster physics, and mass spectrometry form analytical sciences. In this paper, we describe the development of the cluster source and of a double focusing mass spectrometer leading to the production of intense beams of mass selected protonated molecular clusters.

\footnotetext{
${ }^{1}$ J. A. van Kan, F. Zhang, C. Zhang, A. A. Bettiol, and F. Watt, Nucl. Instrum. Methods Phys. Res. B 266, 1676 (2008).

${ }^{2}$ C. Lecas, in Irradiation proposed to treat food, Food \& Drug Administration, FDA Consumer, FAO/IAEA/WHO International Conference on ensuring the safety and quality of food through radiation processing, Antalya, Turkey, 19-22 October 1999, p. 11-13.
} 
${ }^{3}$ B. Göran and G. Bengt, Acta Oncol. 44(8), 881 (2005).

${ }^{4}$ G. Charest, B. Paquette, D. Fortin, D. Mathieu, and L. Sanche, J. Neuro-oncol. 97, 187 (2010).

${ }^{5}$ L. Sanche, Nature (London) 461, 358 (2009).

${ }^{6}$ S. Bari, P. Sobocinski, J. Postma, F. Alvarado, R. Hoekstra, V. Bernigaud, B. Manil, J. Rangama, B. Huber, and T. Schlathölter, J. Chem. Phys. 128, 074306 (2008).

${ }^{7}$ J. Tabet, S. Eden, S. Feil, H. Abdoul-Carime, B. Farizon, M. Farizon, S. Ouaskit, and T. D. Märk, Phys. Rev. A 81, 012711 (2010); 82, 022703 (2010).

${ }^{8}$ G. V. Buxton, C. L Greenstock, W. Ph. Helman, and A. B. Ross, J. Phys. Chem. Ref. Data 17(2), 513 (1988).

${ }^{9}$ M. S. Kreipl, W. Friedland, and H. G. Paretzke, Radiat. Environ. Biophys. 48, 11 (2009).

${ }^{10}$ P. Auffinger and E. Westhof, J. Mol. Biol. 300, 1113 (2000).

${ }^{11}$ A. Kantrowitz and J. Grey, Rev. Sci. Instrum. 22, 328 (1951).

${ }^{12}$ O. F. Hagena, Rev. Sci. Instrum. 63, 2374 (1992).

${ }^{13} \mathrm{~S}$. Legendre, "Etude de l'ionisation et de la dissociation d' $\mathrm{H}_{2} \mathrm{O}$ induites par collision avec des ions multichargés rapides," $\mathrm{Ph} . \mathrm{D}$. dissertation (Université de Caen, 2006).
${ }^{14}$ G. Bruny, "Production et caractérisation d'agrégats moléculaires protonés contenant un nombre donné de molécules d'eau auprès du dispositif DIAM," Ph.D. dissertation (Université Lyon 1, 2010).

${ }^{15}$ SIMION 3D 7.0 (c): D.A. Dahl, Scientific Instrument Services Inc., Boise Idaho 2000.

${ }^{16}$ The thermal energy, kT, at room temperature is $\sim 30 \mathrm{meV}$ so that at least the ions would have the corresponding initial velocity.

${ }^{17}$ M. M. Harb, S. Cohen, E. Papalazarou, F. Lépine, and C. Bordas, Rev. Sci. Instrum. 81, 125111 (2010).

${ }^{18} \mathrm{H}$. Liebl, Applied Charged Particle Optics (Springer-Verlag, Berlin, 2008).

${ }^{19} \mathrm{G}$. Hadinger, Accélération et analyse de fragments d'ADN à l'aide d'un spectromètre de masse, LYCEN RI 2000/57, HAL: in2p3-00009748, (2000).

${ }^{20}$ M. C. Sicilia, A. Nino, and C. Munoz-Caro, J. Phys. Chem. A 109, 8341 (2005).

${ }^{21}$ Y. Li, R. Lu, Y. Hu, and X. Wang, Chem. Phys. Lett. 333, 153 (2001).

${ }^{22}$ Z. P. Wang, P. M. Dinh, P.-G. Reinhard, E. Suraud, G. Bruny, C. Montano, S. Feil, S. Eden, H. Abdoul-Carime, B. Farizon, M. Farizon, S. Ouaskit, and T. D. Märk, Int. J. Mass. Spectrom. 285, 143 (2009). 